\title{
The Chemistry of Flower Rewards - Oncidium (Orchidaceae)
}

\author{
Mariza G. Reis ${ }^{a}$, Aparecida D. de Faria ${ }^{b}$, Volker Bittrich ${ }^{b}$, \\ Maria do Carmo E. Amaral ${ }^{b}$ and Anita J. Marsaioli ${ }^{a_{*}}$
}

\author{
anstituto de Química Universidade Estadual de Campinas, CP 6154, 13083-970, Campinas - SP, Brazil \\ ${ }^{\mathrm{b}}$ Instituto de Biologia, Universidade Estadual de Campinas, CP 6109, 13083-970, Campinas - SP, Brazil
}

\begin{abstract}
A maioria dos estudos sobre polinização focalizam as interações que envolvem recompensas como néctar e pólen. Nosso grupo de pesquisa, entretanto tem se dedicado à química de recompensas florais como resinas e óleos florais. Neste trabalho, estamos relatando a composição química dos óleos florais de Oncidium pubes que contêm di e triacilglicerois nos quais o glicerol está esterificado com um ou dois resíduos de ácido acético e um ácido graxo. O padrão de substituição dos dracilgliceróis foi sugerido com base nas analises espectroscópicas e por comparação com os 3 compostos sintetisados a partir do D-manitol, ácido acético e ácido oleico Finalmente, nossos resultados forneceram evidências químicas de que a polinização de Oncidium pubes não está baseada num mecanismo de atração-engano dos visitantes florais mas na sua recompensa com lipídios florais. Este é o primeiro relato sobre a composição química dos óleos florais de Oncidium pubes (Orchidaceae).
\end{abstract}

Most of the flower-pollinator interactions are based on rewards as pollen and nectar. Our group however, has been focusing on the chemical composition of unusual rewards like floral resins and floral oils. We are now reporting the chemistry of the floraloils of Oncidium pubes which are composed of diacylglycerols and triacylglycerols possessing one or two acetyl residues and one long chain fatty acid. The substitution pattern of some of the diacylglycerols was inferred to be 1,3 based on spectroscopic analyses and comparison with 3 different synthetic compounds obtained from D-mannitol, oleic acid and acetic acid. The fatty acid residues possess double bond and/or acetoxy group as functional groups. Finally our results provided chemical evidences that pollination of Oncidium pubes is not based upon an attraction-deception system but on floral lipids and this is the first time this has ever been mentioned in the literature.

Keywords: Orchidaceae, Oncidium pubes, floral lipids, ( $\beta$-acetoxy-octadecanoyl)-acetyl-glycerol and ( $\beta$-acetoxy-eicosenoyl)- acetyl-glycerol

\section{Introduction}

Most flowers and their pollinating organisms are involved in mutualistic relationships composing an important issue of the chemical ecology. Insect-pollinated flowers usually show adaptations to their pollinators ${ }^{1,2}$. From the chemical ecology point of view the flower-insect relationships can be summarized as: 1 - flower attracts the pollinators (scent and color); 2 - pollinators visit the flowers in search of a reward (nectar, pollen, other food, nest building material etc); 3 - pollen is transferred from the flowers to pollinators and vice-versa ${ }^{3}$.

Pollen and nectar are the most common rewards offered by flowers and probably present in early angiosperms, with pollen preceding nectar as pollinator reward ${ }^{4}$. Floral resins and oils are unusual rewards limited to relatively few

\footnotetext{
* e-mail: anita@iqm.unicamp.br
}

genera $^{5-7}$. The terms floral resin (viscous liquid) and floral oil (fluid liquid) are used to describe nonvolatile chemicals secreted by flowers. Our group is particularly interested in bee pollinated plants offering oils and resins as floral rewards instead of pollen and nectar. We will therefore make some comments on the rewards in the genus Tovomita (Clusiaceae), Clusia (Clusiaceae), Oncidium (Orchidaceae) and we will comment on the chemistry tethering the ecological interactions in these three genera.

In many species of Clusia, a genus with about 250 species, the flowers produce floral resins. The viscous liquid is collected by female bees and used as a nest construction material ${ }^{8}$. Investigations of the chemistry of the floral resins revealed that these are composed of almost pure polyisoprenylated benzophenones ${ }^{5,8-10}$. The attractive effect of Clusia flowers offering resin on some social (Trigonini and Meliponini) and solitary (Euglossini) bees acting as pollinators was indeed observed in field experiments. 
The investigation of petal fragrances of 16 different species of Clusia was recently concluded ${ }^{11}$ and the results indicated that a partial correlation could be established between the chemical composition, the taxonomic sections of the genus Clusia and their pollinators.

We have also studied more than 15 Clusia floral resins from the sections Chlamydoclusia, Cordylandra, Phloianthera, and Polythecandra and in all instances the major components are polyisoprenylated benzophenones type I and type II (Figure 1) $5,8-10$.<smiles>[R]C1C(=O)C(C(=O)c2ccccc2)C(=O)C([R])([R])C1=O</smiles>

Type I $\mathrm{R}_{1}, \mathrm{R}_{2}, \mathrm{R}_{3}=$ isoprenyl

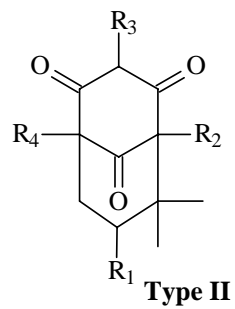

$\mathrm{R}_{1}, \mathrm{R}_{2}, \mathrm{R}_{3}, \mathrm{R}_{4}=$ isoprenyl and benzoyl
Figure 1. Chemical structures of major Clusia floral resin constituents.

Fragrant floral oils are also very rare pollinator rewards 13,14 . We observed that such oils are offered to Euglossa males in Tovomita (Clusiaceae), a neotropical genus with ca. 80 species of dioecious trees distributed in Central America, the Amazon and the Brazilian Atlantic rain forests. The flowers are diurnal and last one day. On the day of anthesis the filaments of the stamens (male flowers) or staminodes (female flowers) produce tiny droplets of fragrant oil which is collected by pollinators - Euglossa males. They land on the stamens and collect the oil while sitting on the anthers. Thus their whole sternum is dusted with the dry pollen. Landing on the large stigmas of the female flowers and collecting the oil from the staminodes while sitting on it, pollination is guaranteed. Small beetles also collect the oil but are considered oil thieves and not pollinators. The fragrant floral oils have been analyzed (T. macrophylla, $T$. rubella and $T$. acutiflora) and their constituents are terpenoids, indole and in T. acutiflora dehydrophytol is the major component $(91.6 \%)^{13}$.

So far we have mentioned four different types of floral rewards (pollen, nectar, resins and oils composed of terpenes) and the fifth is floral oil constituted by lipids. The latter has been discovered by Vogel ${ }^{15-18}$ in floral oils of Calceolarea pavonii (Scrophulariaceae) which were characterized by mass spectrometry and ${ }^{1} \mathrm{H}$ NMR. He further compared, by TLC, the floral oils of C. pavonii, with other plant species belonging to four additional families (Irididaceae, Malpighiaceae, Krameriaceae and Orchidaceae) and concluded that all these floral oils behaved as those of $C$. pavonii and were lipids. Nowadays the list of flowers offering fatty acid derivative oils instead of, or in addition to, nectar and/or pollen consists 79 genera of plants, divided into 10 families and 8 orders and are most abundant in neotropical savannas and forest $\mathrm{t}^{19-23}$. Reaction with crystals of Sudan IV is the major chemical tool in the characterization of this class of compound adding no further structural informations ${ }^{24}$. These oil producing flowers are visited and pollinated by oil collecting bees (usually female bees) found in two families (Melittidae and Apidae) ${ }^{23}$. Singer and Cocucci ${ }^{25}$ have recently observed oil-collecting bees (Anthophoridae: Tetrapedia) visiting Oncidium paranaensis flowers and one specimen was carrying the pollinaria. It was thus concluded that these bees were responsible for pollination.

A search in the literature revealed that the chemistry of Oncidium has been investigated in a screening of the alkaloid content using several reagents, the phytochemical analysis, was not pursued any further ${ }^{26}$. Phenanthrene derivatives were isolated from Oncidium cebolleta leaves 27 and the floral fragrance components of four Oncidium species were investigated by Roman Kaiser ${ }^{28}$. The presence of floral oil in Oncidium ornithorrhynchum (Orchidaceae) was briefly mentioned by $\operatorname{Vogel}^{29}$ when comparing Calceaolarea pavonii floral oils (diacylglycerol and triacyglycerol) to several other floral oils by thin layer chromatography without any further chemical or spectroscopic characterization. Therefore conscious that the composition of Oncidium floral rewards have never been investigated from the chemistry point of view we focused on Oncidium pubes Lindl., one of the many Orchidaceae species from Atlantic rain forest, São Paulo, Brazil under investigation in our group.

\section{Experimental}

\section{General}

FT-IR spectra were recorded with a Perkin Elmer 298 spectrophotometer. ${ }^{1} \mathrm{H}$ NMR spectra were recorded with a Varian GEMINI $300(300.1 \mathrm{MHz}$, Varian) or Varian INOVA (500 MHz) spectrometers, $\mathrm{CDCl}_{3}$ was used as the solvent, with $\mathrm{Me}_{4} \mathrm{Si}$ (TMS) as internal standard. ${ }^{13} \mathrm{C} \mathrm{NMR}$ spectra were obtained with a Varian GEMINI $300(75.5 \mathrm{MHz})$, or a Varian INOVA 500 (125 MHz) spectrometers. $\mathrm{CDCl}_{3}(77.0$ ppm) was used as internal standard. Methyl, methylene, methine and carbon nonbonded to hydrogen were discriminated using DEPT- $135^{\circ}$ and DEPT-90 ${ }^{\circ}$ spectra (Distortionless Enhancement by Polarization Transfer). The homo and heteronuclear 2D NMR correlation experiments were obtained at 11 tesla (Varian Inova 500 spectrometer) 
in $\mathrm{CDCl}_{3}$ solution with a $5 \mathrm{~mm}$ broad band probe (normal configuration). Optical rotation values were measured with a Polamat A polarimeter in a $1 \mathrm{dm}$ cuvette. Melting point values were measured with a Microquímica apparatus and are uncorrected. The GC/MS analyses were carried out using a HP-5890/5970 system equipped with J. \& W. Scientific HP-5 fused silica capillary column (30 m x 0.25 $\mathrm{mm} \times 0.25 \mu \mathrm{m})$; column temperatures were programmed from $50^{\circ}$ to $290^{\circ}$ at $4 \% \mathrm{~min}$, and $15 \mathrm{~min}$ at $290^{\circ}$, the carrier gas was helium. Injector and interface temperature were $250^{\circ}$ and $285^{\circ}$ respectively. The MS were taken at $70 \mathrm{eV}$. Scanning speed was $0.84 \mathrm{scan} / \mathrm{s}$ from $\mathrm{m} / \mathrm{z} 40$ to 700 . The retention indices were obtained by co-injecting the oil and the standards with a $\mathrm{C}_{11}-\mathrm{C}_{30}$ normal hydrocarbon mixture and applying the appropriate equation ${ }^{30}$. HRMS were carried out using a Micromass VG Auto Spec. spectrometer operating at $70 \mathrm{eV}$.

\section{Plant material}

Blossoming Oncidium pubes specimens were collected in Atibaia, São Paulo state, Brazil and the floral oil was collected from the elaiophores gland by scraping them with small glass capillaries ( $0.25 \mathrm{~mm}$ diameter) which were then dumped into vials containing organic solvents (ethyl acetate) or absorbed on filter paper bands. 50 flowers were used to obtain 3.5 miligrams of floral oil. Voucher specimens have been deposited at the Universidade Estadual de Campinas (UEC-110.433) Herbarium with voucher number E. R. Pansarin, 547, Oncidium pubes.

The floral oil was derivatized with diazomethane before the GC/MS analysis

\section{Syntheses of standards}

\section{1-Oleoyl-glycerol 8}

Commercial (ca. 50\% purity) oleic acid ( $2.4 \mathrm{~g}$, about $4.2 \mathrm{mmol}$ ) was added to 2,3-O-isopropylidene-glycerol $7^{37-39}(1 \mathrm{~g}, 8 \mathrm{mmol})$ and 4-dimethylamino-pyridine, DMAP, $(0.01 \mathrm{~g})$ in dichloromethane $\left(31 \mathrm{~cm}^{3}\right)$, at $0^{\circ} \mathrm{C}$ under nitrogen. To the stirred mixture 1,3-dicyclohexylcarbodiimide, DCC, $(1.7 \mathrm{~g}, 8.3 \mathrm{mmol})$ was added and after $20 \mathrm{~h}$ at room temperature the reaction mixture was filtered over a Celite ${ }^{\circledR}$ pad. The solvent was evaporated under vacuum and the resulting mixture was submitted to silica gel chromatography eluted with hexane:ethyl acetate $(9: 1 \mathrm{v} / \mathrm{v})$ furnishing 2,3-isopropylidene-1-oleoyl-glycerol (0.367 g, 25\% yield) as a colorless oil: ${ }^{1} \mathrm{H}$ NMR $\left(300 \mathrm{MHz} ; \mathrm{CDCl}_{3}\right) \delta 0.88(\mathrm{t}, J 6.9 \mathrm{~Hz}, 3 \mathrm{H}), 1.26(\mathrm{~m}, 20 \mathrm{H})$, 1.37 (s, 3H), 1.44 (s, 3H), $1.62(\mathrm{~m}, 2 \mathrm{H}), 2.01(\mathrm{~m}, 4 \mathrm{H}), 2.34$ $(\mathrm{t}, J 7.6 \mathrm{~Hz}, 2 \mathrm{H}), 3.73(\mathrm{dd}, J 6.3$ and $8.5 \mathrm{~Hz}, 1 \mathrm{H}), 4.08$ (dd,
$J 6.6$ and $8.5 \mathrm{~Hz}, 1 \mathrm{H}), 4,09$ (dd, $J 6.3$ and $11.5 \mathrm{~Hz}, 1 \mathrm{H}), 4.17$ (dd, $J 4.6$ and $11.5 \mathrm{~Hz}, 1 \mathrm{H}), 4.31(\mathrm{~m}, 1 \mathrm{H}), 5.35(\mathrm{~m}, 2 \mathrm{H}) .{ }^{13} \mathrm{C}$ NMR (75.45 MHz, $\mathrm{CDCl}_{3}$ ): $\delta 14.07,22.65,24.83,25.35$, $26.63,27.11,27.17,29.04,29.11,29.21,29 \div .29,29.41$, 29.51, 29.64, 29.72, 31.9, 34.06, 64.48, 66.29, 73.61, 109.78, 129.70, 130.00, 173.60. HRMS ( $\mathrm{m} / \mathrm{z})$ Found: M 396.3239; Calc. for $\mathrm{C}_{24} \mathrm{H}_{44} \mathrm{O}_{4}$ : 396.3238 .

A solution of 2,3-isopropylidene-1-oleoyl-glycerol $(100 \mathrm{mg}, 4 \mathrm{mmol})$ in acetic acid/water $70 \% .\left(0.6 \mathrm{~cm}^{3}\right)$ was stirred for $6 \mathrm{~h}$ at $55^{\circ} \mathrm{C}$. The solvent was evaporated under vacuum and the residue was purified by silica column eluted with hexane:ethyl acetate $(5: 5 \mathrm{v} / \mathrm{v})$ yielding 1-oleoyl-glycerol 3 (84 mg, 93\%) as an colorless oil: ${ }^{1} \mathrm{H}$ NMR $\left(300 \mathrm{MHz} ; \mathrm{CDCl}_{3}\right) \delta 0.88(\mathrm{t}, J 6.9 \mathrm{~Hz}, 3 \mathrm{H}), 1.27(\mathrm{~m}$, $20 \mathrm{H}), 1.63$ (m, 2H), 1.85 (bs, 1H), 2.03 (m, 4H), 2.35 (t, $J$ $7.7 \mathrm{~Hz}, 2 \mathrm{H}), 2.80(\mathrm{bs}, 1 \mathrm{H}), 3.59(\mathrm{dd}, J 5.9$ and $11.3 \mathrm{~Hz}, 1 \mathrm{H})$, $3.70(\mathrm{dd}, J 5.9$ and $11.7 \mathrm{~Hz}, 1 \mathrm{H}), 3.93(\mathrm{~m}, 1 \mathrm{H}), 4.17(\mathrm{~m}, 2 \mathrm{H})$, $5.33(\mathrm{~m}, 2 \mathrm{H}) .{ }^{13} \mathrm{C}$ NMR $\left(75.45 \mathrm{MHz}, \mathrm{CDCl}_{3} / \mathrm{TMS}\right): \delta$ 14.08, 22.64, 24.85, 27.12, 27.18, 29.06, 29:11, 29.21, 29.29, 29.48, 31.89, 32.59, 34.12, 63.31, 65.11, 70.23, 129.68, 130.00, 174.35. HRMS ( $\mathrm{m} / \mathrm{z})$ Found: M 398.3032; Calc. for $\mathrm{C}_{21} \mathrm{H}_{44} \mathrm{O}_{6}$ : 398.2968, GC/MS: $(\mathrm{RRI}=2714) \mathrm{m} / \mathrm{z}$ (rel. int.): 265(15), 264(65), 98 (60\%), 55 (100\%).

\section{1-Oleoyl-3-acetyl-glycerol 9}

A mixture of acetic anhydride $(7.5 \mathrm{mg}, 0.1 \mathrm{mmol})$ and pyridine $\left(0.5 \mathrm{~cm}^{3}\right)$ was added dropwise to a solution of 1oleoyl-glycerol $(26.00 \mathrm{mg}, 0.07 \mathrm{mmol})$ in pyridine. After stirring the reaction mixture for $1 \mathrm{hr}$ at r.t. the reaction mixture was submitted to the usual work-up yielding a residue that was purified by silica gel chromatography eluted with hexane:ethyl acetate $(6: 4 \mathrm{~V} / \mathrm{V})$ yielding $9(18 \mathrm{mg}, 62 \%$ yield) as an colorless oil: ${ }^{1} \mathrm{H}$ NMR $\left(300 \mathrm{MHz} ; \mathrm{CDCl}_{3}\right) \delta$ 0.88 (t, J 6.9 Hz, 3H), 1.27 (m, 20H), $1.62(\mathrm{~m}, 2 \mathrm{H}), 2.01$ (m, $4 \mathrm{H}), 2.08(\mathrm{~s}, 3 \mathrm{H}), 2.35(\mathrm{t}, J 7.3 \mathrm{~Hz}, 2 \mathrm{H}), 4.20(\mathrm{~m}, 5 \mathrm{H}), 5.35(\mathrm{~m}$, 2H). ${ }^{13} \mathrm{C}$ NMR (75.45 MHz, $\left.\mathrm{CDCl}_{3} / \mathrm{TMS}\right): \delta 14.10,20.78$, 22.65, 24.85, 27.14, 27.20, 29.06, 29.13, 29.30, 29.50, 29.66, 29.74, 31.89, 34.06, 65.00, 65.22, 68.28, 129.70, 130.02, 171.07, 173.92. HRMS ( $\mathrm{m} / \mathrm{z}$ ) Found: M 398.2968; Calc. for $\mathrm{C}_{23} \mathrm{H}_{42} \mathrm{O}_{5}: 398.3032$, GC/MS: (RRI = 2810) $\mathrm{m} / \mathrm{z}$ (rel. int.): 380.2861 (1), 264.2280 (3), 265 (4), 117 (42), 43 (100).

\section{1-Oleoyl-2, 3-diacetyl-glycerol 10}

A 1:1 mixture of acetic anhydride and pyridine $\left(1 \mathrm{~cm}^{3}\right)$ was added dropwise to a solution of 1-oleoyl-glycerol (11.50 $\mathrm{mg}, 0.03 \mathrm{mmol}$ ) in pyridine. After stirring the reaction mixture for $4 \mathrm{hr}$ at r.t. the reaction mixture was submitted to the usual work-up yielding a residue that was purified by silica gel chromatography eluted with hexane:ethyl acetate (6:4) yielding 10 (13.5 mg, 96\% 
yield) as an colorless oil. ${ }^{1} \mathrm{H}$ NMR $\left(300 \mathrm{MHz} ; \mathrm{CDCl}_{3}\right)$ $\delta 0.88(\mathrm{t}, J 7.0 \mathrm{~Hz}, 3 \mathrm{H}), 1.28(\mathrm{~m}, 20 \mathrm{H}), 2.02(\mathrm{~m}, 4 \mathrm{H}), 2.08$ (s, 3H), $2.09(\mathrm{~s}, 3 \mathrm{H}), 2,31(\mathrm{t}, J 7.7 \mathrm{~Hz}, 2 \mathrm{H}), 4.15(\mathrm{~m}, 2 \mathrm{H})$, $4.29(\mathrm{~m}, 2 \mathrm{H}), 5.26(\mathrm{~m}, 1 \mathrm{H}), 5.36(\mathrm{~m}, 2 \mathrm{H}) .{ }^{13} \mathrm{C} \mathrm{NMR}(75.45$ $\left.\mathrm{MHz}, \mathrm{CDCl}_{3} / \mathrm{TMS}\right) \delta 14.10,20.68,20.87,22.67,24.82$, $27.14,27.20,29.04,29.08,29.14,29,30,29.50,29.68$, 29.74, 31.88, 34.00, 61.97, 62.28, 69.09, 129.71, 130.00, 170.10, 170.52, 173.30. HRMS ( $\mathrm{m} / \mathrm{z}$ ) Found: M 440.3133; Calc. for $\mathrm{C}_{25} \mathrm{H}_{44} \mathrm{O}_{6}: 440.3137, \mathrm{GC} / \mathrm{MS}$ : $(\mathrm{RRI}=2897) \mathrm{m} / \mathrm{z}$ (rel. int.): 380 (1), 264 (6), 265 (4), 159 (50), 43 (100).

\section{Results and Discussion}

The GC/MS analysis revealed that the Oncidium pubes floral oil was mainly composed by di- and triacylglycerols (RRI 2910 to 3257) (Figure 2) responsible for at least $70 \%$ of the total oil contents.
It was further observed that several compounds present in the oil mixture displayed a fragmentation pattern $\left(m / z, 117,159\right.$ and $\left.325+\mathrm{nCH}_{2}-\mathrm{AcOH}, \mathrm{n}=0,2\right)$ compatible with glycerol derivatives possessing long chain fatty acid and acetyl residues. A search in the literature revealed that acylglycerol isomers display similar fragmentation patterns, ${ }^{31}$ difficulting the identification of such compounds based on the mass spectral data comparison. In such circumstances the relative retention indices are helpful but these were not available. We have therefore, proposed the structure of the major components as (acetoxy-octadecanoyl)-acetylglycerol $($ RRI $=2910$, peak 2, Figure 2), (acetoxyoctadecenoy)-acetyl-glycerol (RRI = 3097, peak 4, Figure 2). Among the minor long chain glycerol derivatives, we have detected octadecenoyl-diacetyl-glycerol (RRI = 2973, peak 3, Figure 2) (Table 1).

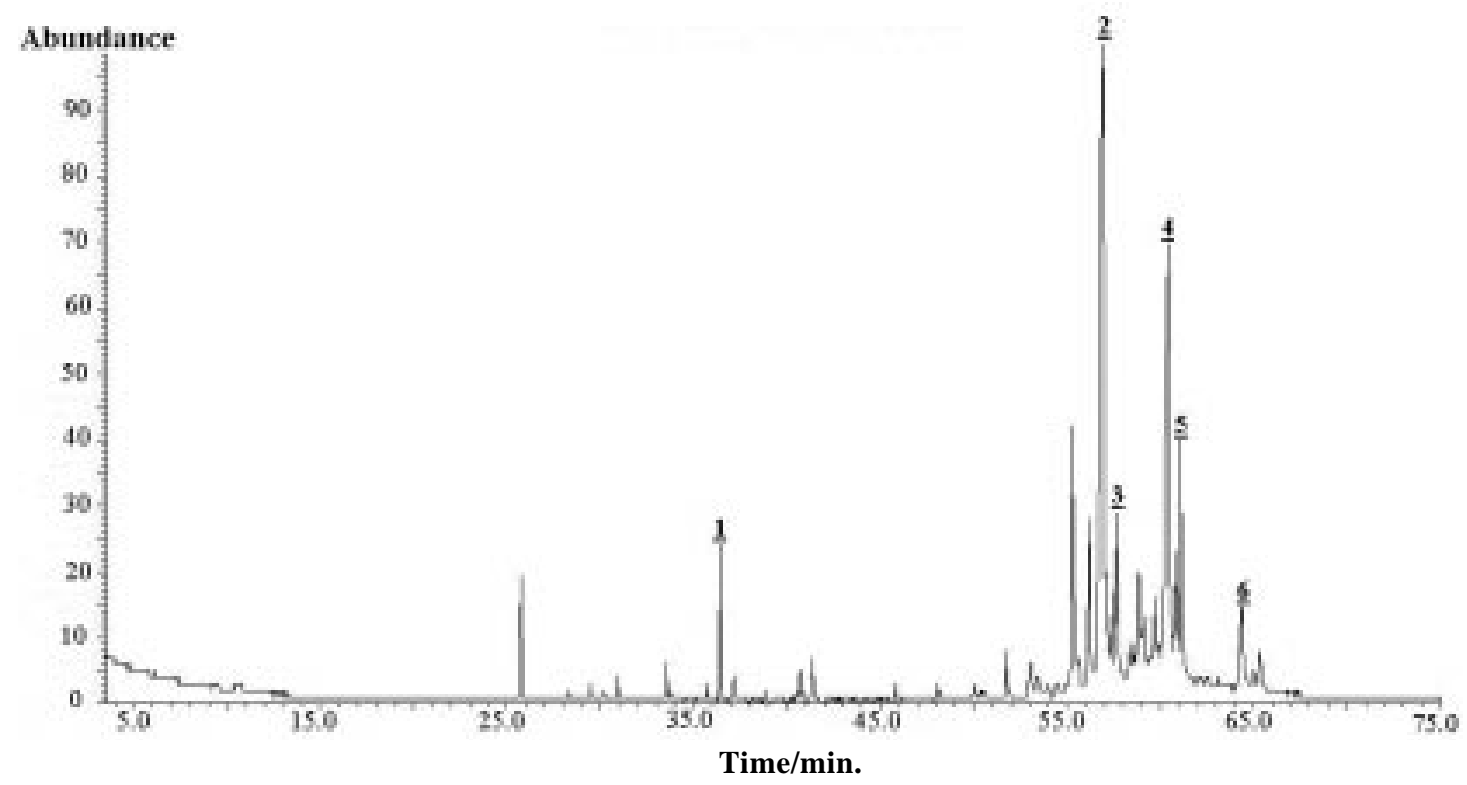

Figure 2. Total ion chromatogram of the Oncidium pubes floral oil (HP-5 column, $30 \mathrm{~m} \mathrm{X} 0.25 \mathrm{~mm} \times 0.25 \mu \mathrm{m}$ ) with the peak numbers corresponding to the identification of the compounds cited in Table 1.

Table 1. Chemical composition of Oncidium pubes floral oil

\begin{tabular}{ccccc}
\hline Peak\# & Compound & RRI $_{\mathrm{a}}$ & Relative abundance $(\%)$ & MS $m / z(\%)$ \\
\hline $\mathbf{1}$ & Palmitic acid methyl ester & 1974 & 1,9 & $74(100), 87(58), 270(5)$ \\
$\mathbf{2}$ & $(\beta$-acetoxy-octadecanoyl)-acetyl-glycerol & 2910 & 33,2 & $43(100), 117(24), 265(48), 325(5), 380(1)$ \\
$\mathbf{3}$ & octadecenoyl- diacetyl- glycerol & 2973 & 4,7 & $43(100), 159(48), 264(8), 265(24), 380(1)$ \\
$\mathbf{4}$ & $(\beta$-acetoxy-octadecenoyl)- acetyl- glycerol & 3097 & 22,6 & $43(100), 117(48), 263(2), 323(1)$ \\
$\mathbf{5}$ & octadecedienoyl- diacetyl- glycerol & 3146 & 5,9 & $43(100), 159(58), 263(4)$ \\
$\mathbf{6}$ & $(\beta$-acetoxy-eicosenoyl)-acetyl - glycerol & 3257 & 3,4 & $43(100), 117(40), 291(3), 351(1)$ \\
- & Total Identified & - & 71,6 & -
\end{tabular}

$\mathrm{RRI}_{\mathrm{a}}$-Relative Retention Index calculated using Van den Dool, ${ }^{30}$ equation (Van den Dool, 1963) and coinjecting a homologous series of normal hydrocarbon mixture; MS- Mass spectrum 
The position of the acetyl groups could either be at position 1,2 or 3 of the glyceryl residue and from the fragmentation pattern and literature data we could neither ascertain the exact position of the substituents nor of the double bonds.

Consequently, bonafide standards were of fundamental importance to obtain relative retention index and mass spectral evidences for structural propositions.

Synthetic standards 8, 9 and 10 were obtained from Dmannitol following Eibl ${ }^{32}$ synthetic approach (Scheme 1).

Peak 3 (Figure 2) had a fragmentation pattern consistent with an octadecenoyl residue we have therefore used, easily available, oleic acid to obtain standards $\mathbf{8 , 9}$ and $\mathbf{1 0}$. The spectral data of standards $\mathbf{8}, \mathbf{9}$ and $\mathbf{1 0}$ were all consistent with the proposed structures.
The mass spectrum of $\mathbf{8}$ showed no molecular ion but the oleoyl residue was easily detected by fragments $\mathrm{m} / \mathrm{z}$ $264(65 \%)$ and $265(15 \%)$. Remaining significant fragments were all assigned to the long chain fatty acid. Comparing the fragmentation pattern of $\mathbf{8}$ and the relative retention index $(\mathrm{RRI}=2714)$ with those of the floral oil of $O$. pubes we concluded that monosubstituted glycerol derivatives were not present.

The mass spectrum of $9(\mathrm{RRI}=2810)$, displayed fragments at $m / z 380\left(\mathrm{M}-\mathrm{H}_{2} \mathrm{O}, 1 \%\right)$ and $117(42 \%$ McLafferty rearrangement, fragment A, Figure 3 and 4) which are diagnostic of the 1,3-diacyl-glycerol substitution with one acetyl and one oleoyl residue and those at $\mathrm{m} / \mathrm{z} 264$ (3\%), $265(4 \%)$ arise from the fatty acid moiety. Comparison of this fragmentation pattern with that

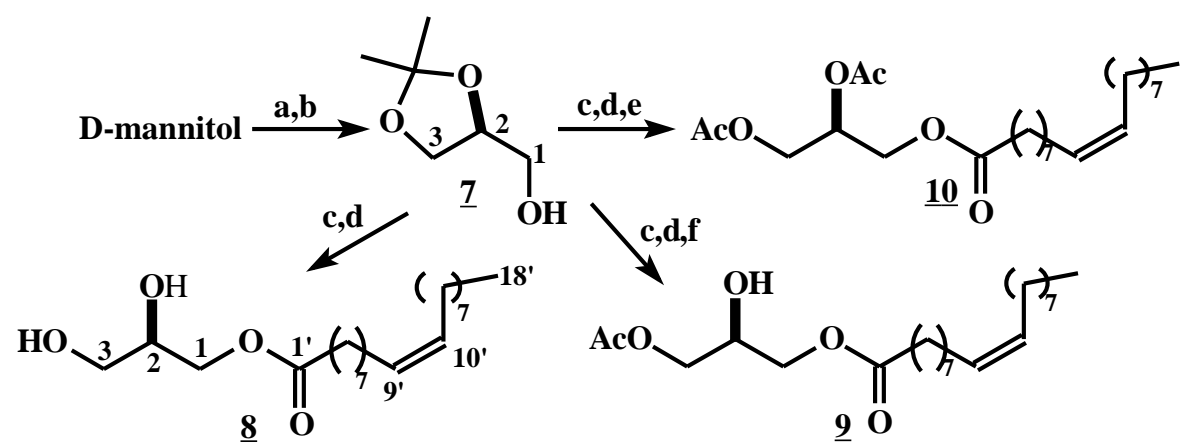

Scheme 1. Synthetic routes to 1-oleoyl-glycerol (8), 1-oleoyl-3-acetyl-glycerol (9) and 1-oleoyl-2,3-diacetyl-glycerol (10). (a)-Acetone/ZnCl ${ }_{2}$, $0^{\circ} \mathrm{C}, 17 \mathrm{~h}$, rt (40\%); (b) $\mathrm{NaIO}_{4} / \mathrm{NaHCO}_{3}$ aq. $1 \mathrm{~h}, 0^{\circ} \mathrm{C}$ followed by $\mathrm{NaBH}_{4}$ /ethanol, $0^{\circ} \mathrm{C}, 2 \mathrm{~h}, \mathrm{rt}, \mathrm{CH}_{3} \mathrm{COOH}, \mathrm{pH}=8,10 \mathrm{~min}, \mathrm{rt}(62 \%)$; (c) oleic acid/ DMAP/DCC, $0^{\circ} \mathrm{C}, 20 \mathrm{~h}, \mathrm{rt}(25 \%)$; (d) $\mathrm{CH}_{3} \mathrm{COOH} / \mathrm{H}_{2} \mathrm{O} 70 \%, 55^{\circ} \mathrm{C}, 5 \mathrm{~h}(93 \%)$; (e) acetic anhydride(excess)/ pyridine 3h, rt (96\%); (f) acetic anhydride/ pyridine $1 \mathrm{~h}, \mathrm{rt}(63 \%)$.

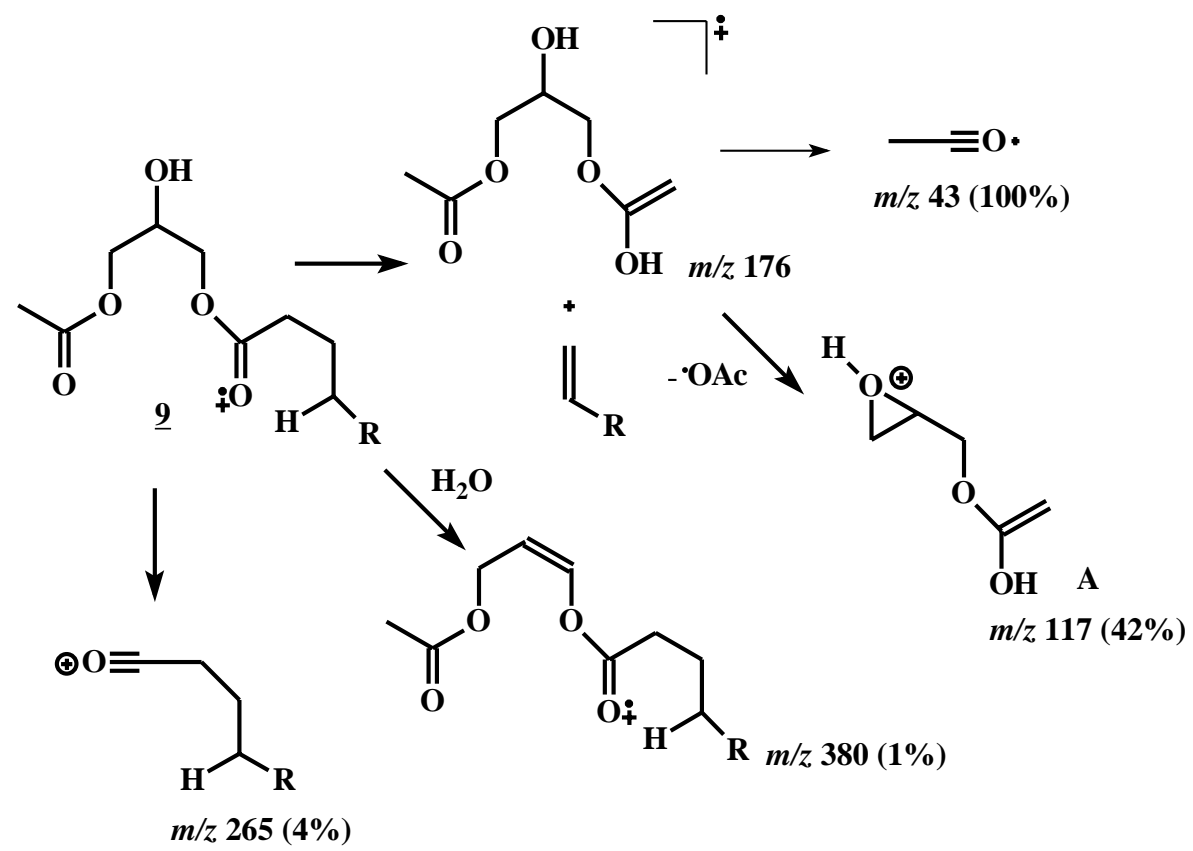

Figure 3. Proposed fragmentation by EIMS of compound $\mathbf{9}$. 
of $\mathbf{1 0}$ revealed that the relevant fragment is at $\mathrm{m} / \mathrm{z} 159$ $(50 \%)$ and is assigned to fragment B (McLafferty rearrangement followed by the loss of an acetyl radical, Figure 5 and 6). Fragments at $m / z, 264,265$ were present in both 9 and $\mathbf{1 0}$ therefore not indicative of any particular glycerol substitution pattern (Figure 4 and 6 ). The fragmentation pattern of these standards was compared to the $O$. pubes floral oil components revealing that 9, 2, 4 and 6 (Figure 3 and 4) had relevant fragments at $\mathrm{m} / \mathrm{z}, 117$ which was taken as indicative of 1-acyl-3-acetyl-glycerol derivatives. The 1-acyl-2-acetyl-glycerol detected by Vogel had two fragments at $m / z 117$ and $159 .{ }^{29}$ Thus the presence of fragments at $\mathrm{m} / \mathrm{z} 159$ (ca. 50\%) in the mass spectra of compounds 10, 3 and 5 (Figure 4 and 5) was taken as a spectroscopic evidence for the 1-acyl-2,3-diacetyl-glycerol substitution pattern. However, Johnson and Holman's mass spectrometry study on lipids indicated that 1-myristoyl- 2,3-diacetyl-glycerol and 2-myristoy 11,3-diacetylglycerol possessed identical mass spectra thus preventing the identification of 1-acyl-2,3-diacetyl and 2-acyl-1,3 diacetyl glycerol derivatives by mass spectra comparison.

Coinjection of 1-oleoyl-2,3-diacetyl-glycerol 10 (RRI 2897 ) with the floral oil showed that the natural product (peak 3, RRI 2973) possessed different relative indices. Thus either substitution pattern or double bond possition in both $\mathbf{1 0}$ and $\mathbf{3}$ are different

From the above results it was obvious that additional spectroscopic evidences were required for the characterization of the compounds present in the mixture and NMR spectroscopy was the alternative choice. The ${ }^{1} \mathrm{H}$ NMR of the floral oil in deuterochloroform was surprisingly simple: two singlets at $\delta 2.04$ and $\delta 2.10$ were assigned to the presence of two different types of acetyl residues: one linked to the glycerol unit $(\delta 2.10)$, inferred by comparison with standards 9 and 10)

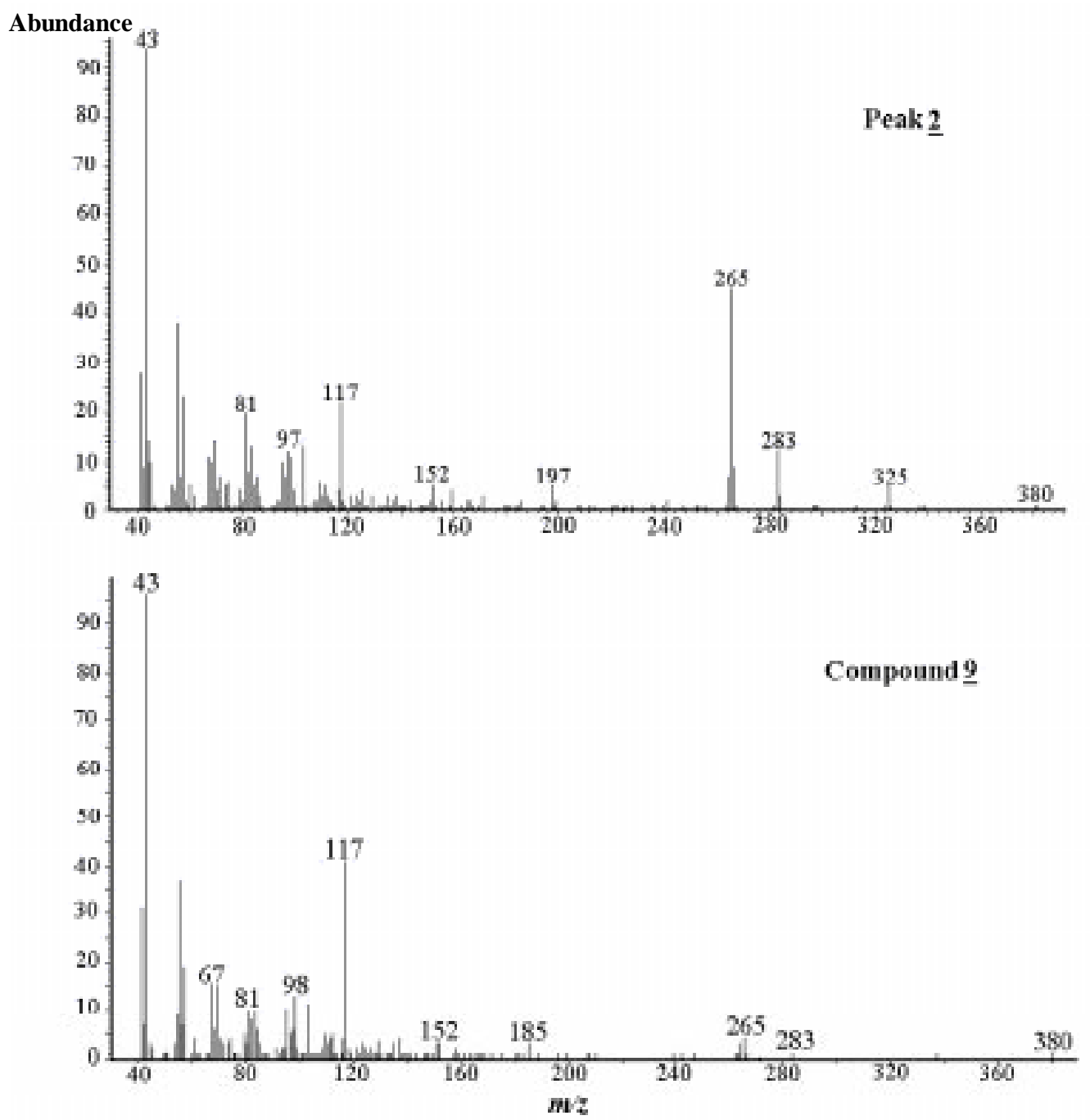

Figure 4. Mass spectra of compound 9 and 2. 


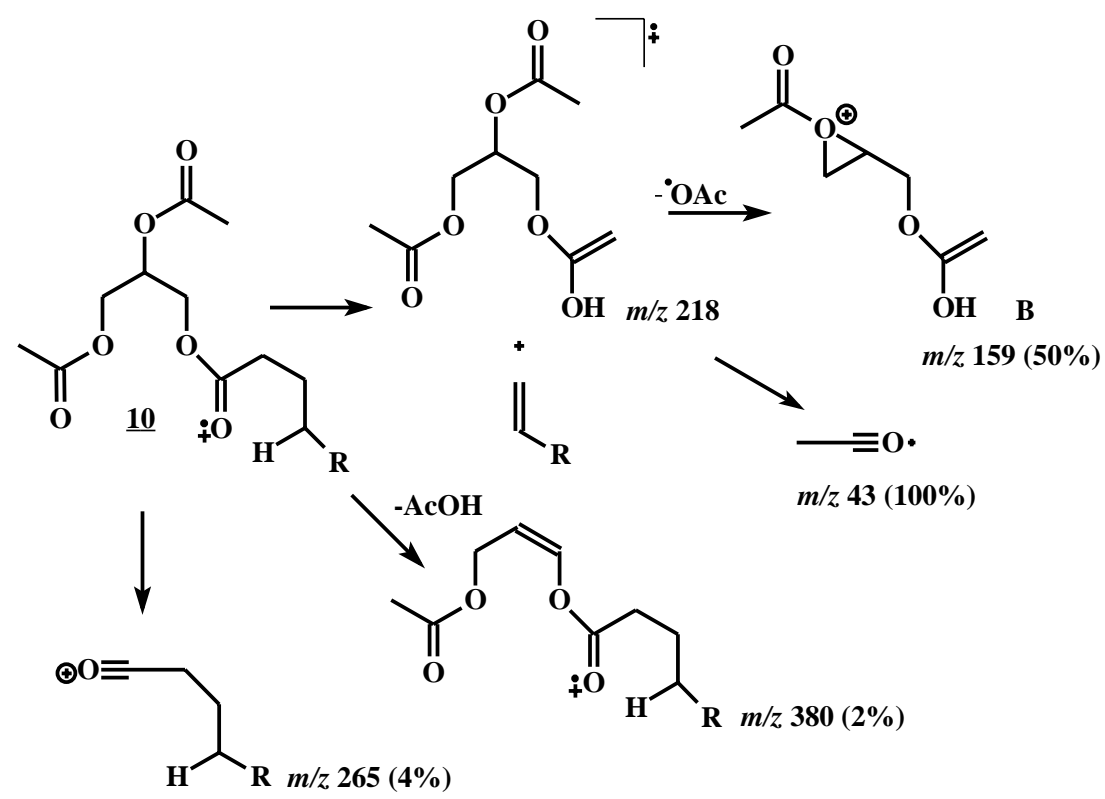

Figure 5. Proposed fragmentation by EIMS of compound $\mathbf{1 0}$.
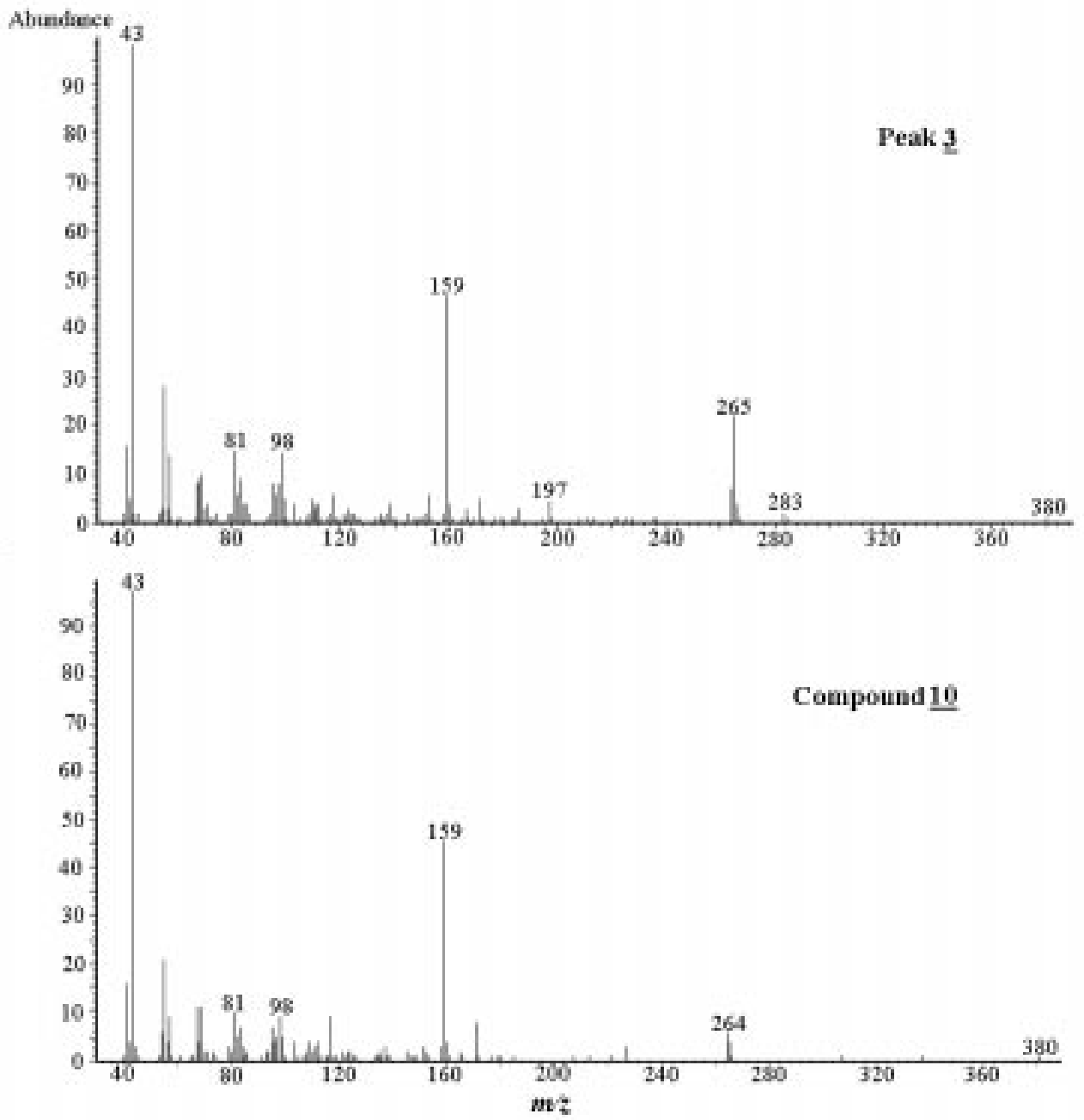

Figure 6. Mass spectra of compound $\mathbf{1 0}$ and $\mathbf{3 .}$ 


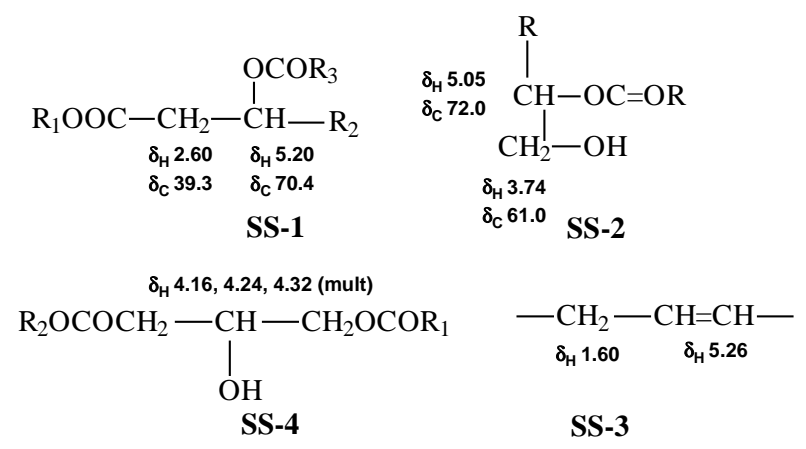

Figure 7. Carbon and Hydrogen chemical shifts of spin systems detected by heteronuclear and homonuclear correlation 2D NMR spectroscopy (HSQC and gCOSY) of Oncidium pubes floral oil.

and the other at the $\beta$-position of the fatty acid residue $(\delta$ $2.04)^{29,33}$. The multiplet at $\delta 2.60$ and the multiplet at $\delta 5.20$ were assigned to the methylene and methine hydrogens $\mathrm{H}-2$ and $\mathrm{H}-3$ of $\beta$-acetoxy-substituted fatty acid residue on a glycerol derivatives by comparison with those reported for the floral oil from Calceolaria pavonii Benth.(Scrophulariaceae) ${ }^{29}$. From the analysis of 2D NMR spectra of the floral oil mixture, depicting one bond correlations between ${ }^{1} \mathrm{H},{ }^{13} \mathrm{C}$ signals (HSQC) and multibond correlations between $\mathrm{H}, \mathrm{H}$ signals (gCOSY) we could infer the presence of several spin systems and the most significant ones are depicted in Figure 7. From these spin systems and their relative abundances, we could ascertain that the $\beta$-acetoxy-fatty acids are major residues (SS1, Figure 7) while unsaturated fatty acid residues are not so abundant (SS-3, Figure 7).

Thus from both analyses we suggest that major constituents of the Oncidium pubes floral oils are 1-acylacetyl-glycerol derivatives with $\beta$-acetoxy-fatty acids as the predominant residues and only additional synthetic work and samples will allow the total structural elucidation.

\section{Conclusion}

This is the first report on the chemistry of floral lipids of Oncidium pubes and it is also the first report on the chemistry of Orchidaceae floral lipids. From these preliminary results we have been able to suggest the floral lipids composition (Table 1) which have been detected by GC/MS. We have thus produced chemical evidence that pollination of Oncidium pubes with flowers that do not offer nectar is not based upon an attraction-deception system ${ }^{25,34-36}$ but on floral lipid rewards. As mentioned in the introduction, floral lipid rewards have been detected in other plant families like Malpighiaceae and Scrophulariaceae which are pollinated by Anthophoridae bee (oil collecting bees). Whether the floral lipids are only used as energy source is a question that remains to be answered but again a team work of chemists and biologists will be required to find all the remaining molecules tethering Oncidium to their pollinating bees.

\section{Acknowledgements}

The authors are indebted to FAPESP and CNPq for financial support and scholarships.

\section{References}

1. Proctor, M.; Yeo, P.; Lack, A. The Natural History of Pollination; Harper Collins Publ.; London, 1996.

2. Harborne, J.B. Nat. Prod. Reports, 1989, 3, 85.

3. Harbone, J.B. Introduction to Ecological Biochemistry. Ed. Academic Press.; San Diego, 1993.

4. Crane, P. R.; Friis, E. M.; Pedersen, K. R. Nature 1995, 374, 27.

5. Lokvam, J., Braddock J. F., Reichardt, P. B.; Clausend, T. P. Phytochemistry, 2000, 55, 29.

6. Vinson, S. B.; Williams H. J.; Frankie, G. W.; Shrum G. Biotropica, 1997, 29, 76.

7. Armbruster, W. S. Amer. J. Bot. 1984, 72, 1149.

8. Oliveira, C. M. A.; Porto, A. L. M.; Bittrich, V.; Marsaioli, A. J. Tetrahedon Lettr. 1996, 37, 7427.

9. Oliveira, C. M. A.; Porto, A. L. M.; Bittrich, V.; Marsaioli, A. J. Phytochemistry 1999, 50, 1073.

10. Porto, A. L. M.; Machado, S. M. F.; Oliveira, C. M. A.; Bittrich, V.; Amaral, M. C. E.; Marsaioli, A. J. Phytochemistry (in press)

11. Nogueira, P. C.; Bittrich, V.; Shepherd, G. J.; Lopes, A. L.; Marsaioli, A. J. Phytochemistry (in press)

12. Curry, K. J.; Mcdowell, L.M.; Judd, W. S.; Stern, W. L. Amer. J. Botany, 1991, 78, 610.

13. Nogueira, P. C.; Marsaioli, A. J.; Amaral, M. C. E; Bittrich, V. Phytochemistry, 1998, 49, 1009.

14. Eltz, T.; Whitten, W. M.; Roubik, D. W.; Linsenmair, K. E. J. Chem. Ecol. 1999, 25, 157.

15. Vogel, S. XI. Abstracts of Intern. Bot. Congr., 1969, 229.

16. Vogel, S. Naturwissenschaften, 1981, 67, 5627.

17. Vogel, S. Ölblumen and Ölsammelnde Bienen: Zweite Folge Lysimachia und Macropis. In Akademie der Wissenschaften und der Literatur Mainz, Frans Steiner Verlg. Stuttgart, Germany. 1986.

18. Vogel, S. Plant Syst. Evol. 1991, 178153.

19. Simpson, B.; Neff, J. L. Ann. Missouri Bot. Gard. 1981, $68,301$.

20. Buchmann, S. L.; Buchmann, M. D. Biotropica (Suppl on Reproduct. Biol.) 1981, 13, 7.

21. Simpson, B. B.; Seigler, D. S.; Neff, J. L. Bioch. Syst. and Ecol. 1979, 7, 193.

22. Buchmann, S. L. Annu. Rev. Ecol. Syst. 1987, 18, 343. 
23. Vinson, S. B.; Williams, H. J.; Frankie, G. W.; Shrum G. Biotropica, 1997, 29, 76.

24. Steiner, K. E. Lindleyana, 1989, 4, 164.

25. Singer, R. B.; Cocucci, A. A. Lindleyana, 1999, 14, 47.

26. Luning, B. Act. Chem. Scand. 1964, 18, 1507.

27. Stermitz, F. R.; Suess, T. R.; Schauer, C. K.; Bye Jr, R. A. J. Nat. Prod. 1983, 46, 417.

28. Kaiser, R. The Scent of Orchids, Olfactory and Chemical Investigations. Elisevier, ed. Roche, Basel. Amesterdan. 1993. 259 pp.

29. Vogel, S. Öblumen und Ölsammelnde Bienen. Akad. Wissenschaften u. Literature Mainz. Wiesbaden: Franz Steiner, 1974. 547 pp.
30. Dool, V. D.; H. Kratz, P.D.J. J. Chrom., 1963, 11, 463. 31. Jonhson, C. B.; Holman, R. T. Lipids, 1966, 1, 371.

32. Eibl, H.; Woolley P. Chem. Phys. Lipids 1986, 41, 53. 33. Seigler, D.; Simpson, B. B.; Martin, C.; Neff, J. Phytochemistry. 1978, 17, 995.

34. Nierenberg, L. Amer. Orchid. Soc. Bull. 1972, 41, 873. 35. Chase, M. W. Syst. Bot. 1986, 11, 477.

36. Ackerman, J. D. Lindleyana, 1986, 1, 108.

37. Schmid, C.R.; Bryant, J. D.; Dowlatzedah, M.; Phillips, J. L.; Prather, D.E.; Schantz, D.R.; Sear, L.N.; Vianco, S. C. J. Org. Chem. 1991, 56, 4056.

38. Chittenden, G. J. F. Carbohydr. Res. 1980, 84, 350. 39. Hubschwerlen, C. Synthesis, 1986, 962

Received: July 24, 2000. 